\title{
Flame retardant polyurethanes based on novel phosphonamidate additives
}

\author{
SABYASACHI GAAN, MATTHIAS NEISIUS, OLIVIA CUCHERE, SHUYU LIANG, \\ HENRI MISPREUVE ${ }^{1}$ \\ Additives and Chemistry Group, Advanced Fibers, EMPA, St Gallen, Switzerland \\ ${ }^{1}$ Foam Partner, Fritz Nauer AG, Wolfhausen, Switzerland
}

\begin{abstract}
Development of new halogen-free flame retardants for application in polymer is becoming important due to ban of some existing halogenated flame retardants, ineffectiveness of existing flame retardant additives and higher fire performance requirements for materials. Polyurethane is an important class of polymer finding application in diverse areas like textile coatings, wood coatings, foams, fibers, cables, adhesives etc. There is a great need to develop halogen free flame retardants for various PU based materials. In this work we have reported synthesis of novel phosphonamidates as flame retardant additives and their application in manufacturing flame retardant flexible PU foams and flame retardant polyester PU coated fabrics. Furthermore the flame retardant properties and thermal decomposition characteristics of the PU based materials have been evaluated. The novel phosphonamidate derivatives have superior fire performance properties as compared to existing commercial flame retardant additives and work primarily in gas phase by recombining $\mathrm{H}^{*}$ and $\mathrm{OH}^{*}$ radicals.
\end{abstract}

KEYWORDS: Flame retardant, phosphonamidates, PU foams, coatings, polyester

\section{INTRODUCTION}

Over the last decade the development of new halogen free flame retardants have been based on novel phosphorus chemistry[1]. Development of new flame retardants exhibiting gas phase inhibition action is important for replacement of halogenated flame retardants that are facing environmental scrutiny[2]. Nitrogen-phosphorus (P-N) based compounds like phosphoramidates (PRs) have attracted some attention in the flame retardant community due to their synergistic interactions. Some phosphoramidate compounds have been shown to primarily act in condensed phase[3]. More recently we have reported efficient flame retardant action of phosphoramidate compounds in flame retardancy of flexible PU foams[4]. Their mode of action was primarily attributed to gas phase inhibition. DOPO (9,10-dihydro-9-oxaphosphaphenanthrene-10-oxide) and some derivatives thereof have drawn much attention in the last decade due to their excellent flame retardant properties[5-7]. It is mainly accepted and investigated in detail that these compounds predominantly act by a gas phase-inhibition mechanism.
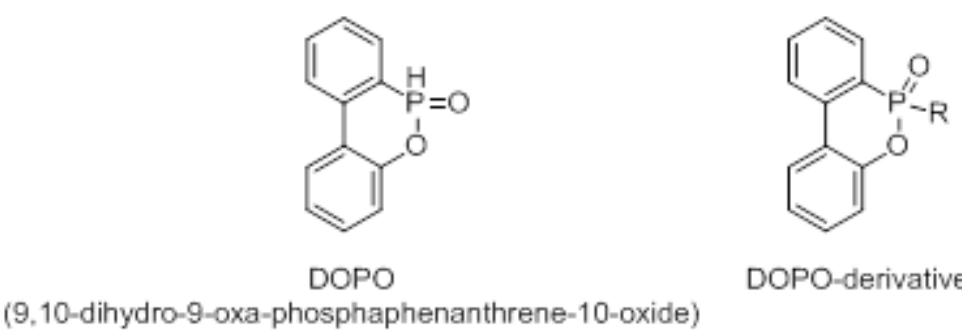

DOPO-derivative

Scheme 1. DOPO and its derivatives 
During combustion they decompose and release low molecular weight phosphorus-containing fragments that are able to recombine $\mathrm{H}^{*}$ and $\mathrm{OH}^{*}$ radicals and thus interrupt the combustion process[8]. In the literature there exists numerous reports dealing with the synthesis and flame retardant application of alkyl DOPO-derivatives[9-11]. Additionally, one can also find several reports dealing with the synthesis and application as flame retardant of alkoxy DOPO-derivatives[12]. In contrast to these derivatives one could find some publications dealing with amino DOPO-derivatives. Although phosphinate derivatives of DOPO are commonly known as flame retardants for various polymeric systems, the amino derivatives of DOPO (phosphonamidates) are not well studied as flame retardants. We have recently reported synthesis and flame retardant application of novel amino-DOPO derivatives (phosphonamidates)[13, 14]. Depending on the nature of amino group linked the phosphorus atom, a great variety of derivatives with varying physical and flame retardant property can be obtained.

Polyurethane is an important class of polymer finding application in wide ranges of products. Flexible polyurethane foam (FPUF) is an important material finding usages in mattresses, furniture cushioning, bedding, carpet underlay, automotive interiors, etc. FPUFs, being highly cellular polymers, are easily ignitable and highly flammable. This characteristic of FPUF limits their greater use in areas which require them to pass certain fire regulations. The fire hazards associated with the use of these polymeric materials, which cause the loss of life and property, are of particular concern among government regulatory bodies, consumers and manufacturers alike. This further necessitates the use of flame retardant (FR) in the manufacturing of FPUFs for reduction in their flammability and smoke/toxic fumes production. A large range of FRs such as inorganic phosphorus, organophosphorus, nitrogen, halogen and phosphorus-halogen based compounds are being used to render FPUF flame retardant[15]. However, the use of most commonly used halogen based FR additives for FPUF, such as Tris(2-chloroethyl) phosphate (TCEP), Tris(1,3dichloroisopropyl) phosphate (TDCPP) and Tris(1-chloro-2-propyl) phosphate (TCPP) is currently restricted because of their potential toxicity and environmental problems arising from FPUF's storage, transportation and combustion[16]. Therefore there is a great need to develop environmental friendly FRs to replace these halogen based compounds.

Polyurethane dispersions are commonly used in coating textiles for applications in sports, medical, clothing, fashion articles, technical articles and general protective equipment. Coated textiles for application in furnishing and upholstery are required to pass certain fire regulations. Usually brominated compounds like decabromodiphenyl ether (Decabrom) together with antimony oxide are used in such coatings[17]Like many other halogenated flame retardants Decbrom will be phased out in near future and there is an immediate need to develop ecofriendly flame retardant alternatives.

In this work we report synthesis of novel amino-DOPO derivatives (phosphonamidates) and their application in flexible polyurethane foams and polyurethane based back coatings of polyester fabrics. The flame retardant characteristics of the modified polyurethane foams and coated textiles have been characterized using several fire tests. Furthermore the mode of action of the phosphonamidates have been evaluated using direct probe MS.

\section{EXPERIMENTAL}

\section{Synthesis of Amino-DOPO Derivatives}

The amino DOPO derivatives were synthesized according to the procedure shown in the scheme 2 .
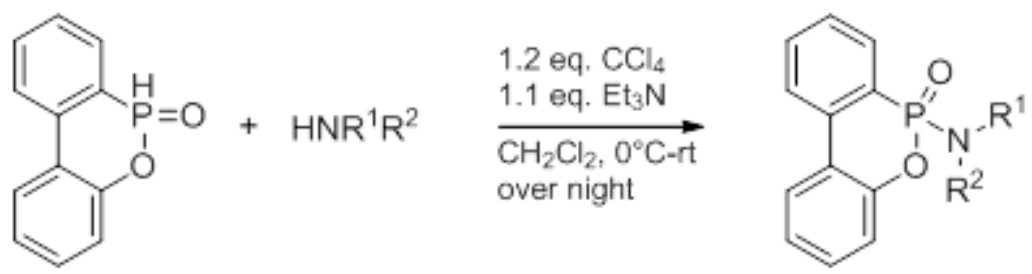

Scheme 2. Synthesis procedure of amino-DOPO derivatives 
9,10-Dihydro-9-oxa-10-phosphaphenanthrene-10-oxide (DOPO) (108 g, $500 \mathrm{mmol}$ ), triethyl amine (79 ml, $566 \mathrm{mmol})$ and the appropriate amine $(240-750 \mathrm{mmol})$ are dis-solved in $400 \mathrm{ml}$ of an appropriate solvent, for example dichloromethane or chloroform, stirred and cooled to $0^{\circ} \mathrm{C}$. After the solution has been cooled down, carbon tetrachloride $(59 \mathrm{ml}, 600 \mathrm{mmol})$ was added dropwise at a rate that the reaction temperature does not exceed $10^{\circ} \mathrm{C}$. After all carbon tetrachloride has been added, the solution is allowed to warm up to room temperature and the stirring is continued until all the starting material has been consumed (observed with TLC). After complete conversion the triethylamine hydrochloride is filtered off and washed with excess of dichloromethane. The resulting clear solution is washed with water $(100 \mathrm{ml})$, dried over $\mathrm{Na}_{2} \mathrm{SO}_{4}$ and the solvent is evaporated in vacuum. If the resulting product does not exhibit enough analytical purity, it is recrystallized from an appropriate solvent. The amino-DOPO derivative was characterized for the chemical structure using HPLC-MS, IR and NMR.

Scheme 3 shows the mono and bis amino-DOPO derivatives which were synthesized in this work.

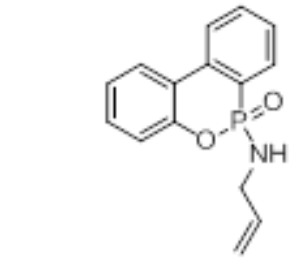

6-(allylamino)-6H-dibenzo[c,e][1,2] oxaphosphinine 6-oxide

(AA-DOPO)

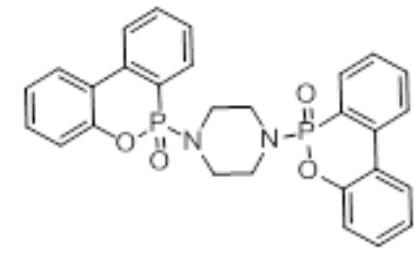

6.6"-(piperazine-1,4-diyl)bis $(6 \mathrm{H}$ dibenzo[c,e][1,2]oxaphosphinine 6-oxide) (Pip-b-DOPO)<smiles>O=P1(NCc2ccccc2)Oc2ccccc2-c2ccccc21</smiles>

6-(benzylamino\}-6H-dibenzo[c,e][1,2] oxaphosphinine 6-oxide (BA-DOPO)<smiles>O=P1(NCCNP2(=O)Oc3ccccc3-c3ccccc32)Oc2ccccc2-c2ccccc21</smiles>

6,6'-\{ethane-1,2-diylbis(azanediyl))bis $(6 \mathrm{H}$ dibenzo[c,e][1,2]oxaphosphinine 6-oxide) (EDA-b-DOPO)

Scheme 3: Synthesized amino- DOPO derivatives 


\section{Foam Preparation}

Flexible polyurethane foams( FPUFs) modified with various amino-DOPO derivatives at different concentrations ( 5 and $10 \mathrm{wt} \%$ based on the weight of applied PO 56), have been prepared on lab scale by mixing of FPUF components: 97 parts propylene oxide polyol (PO 56), softening agent and corresponding amino-DOPO derivatives were mixed by stirring at $1500 \mathrm{rpm}$ (mechanical stirrer) for $1 \mathrm{~min}$, then 0.97 parts water, 0.8 parts emulsifier, 0.5 parts silicone surfactant, 0.8 parts urea, 0.1 parts tertiary amine and 0.25 parts tin (II) octanoate were added and the whole mixture was stirred again for $10 \mathrm{~s}$. That was followed by a final addition of 22.3 parts TDI 80 with stirring for $15 \mathrm{~s}$. The resultant mixture was immediately poured into a $250 \times 100 \times 80 \mathrm{~mm}^{3}$ container to produce free-rise foams. After preparation, the foams were cured in an oven at $80{ }^{\circ} \mathrm{C}$ for 1.5 hours. After conditioning, several samples were cut for further physical and fire characterizations. The apparent density of FPUF was measured according to ISO 845 standard, with specimen bar cut into the dimension of $150 \times 50 \times 13 \mathrm{~mm}^{3}$ (length $\times$ width $\times$ thickness).

\section{PU Coating of Polyester Fabric}

Preparation of coating paste for textiles involved mixing of 100 parts commercially available PU dispersion (Tubicoat PUS) with required parts of pre-dispersed flame retardant additive, 10 parts fixer, 1 part defoamer and 10 parts CMC ( 3.5\% stock ). Three different flame retardant additives were taken for the coating trials i.e. EDA-b-DOPO, Decabrom: antimony trioxide (3:1) and Apyrol FFD. Pre-dispersed flame retardant additive was prepared by milling the flame retardant additive with Dispersogen PTS with at 10: 2 ratio. A4 size polyester textiles were then coated using laboratory coater, dried in oven at $80{ }^{\circ} \mathrm{C}$ and cured at $120^{\circ} \mathrm{C}$ for 5 mins.

\section{Fire Tests}

UL94-HB test was carried out as an indicator to evaluate the flame retardancy of FPUFs in our study. In this test the specimen is oriented in the horizontal position and exposed to a flame at one end. In the test, the flame is applied to the free end of the specimen for 60 seconds and then removed, while cotton was placed under the specimen. After-flame time is noted as tA. The $150 \mathrm{~mm}$-long test specimen is marked on the $25 \mathrm{~mm}, 60 \mathrm{~mm}$ and $125 \mathrm{~mm}$ positions and the burning rate is measured between a $100 \mathrm{~mm}$ span. The dimension of specimen bar is $150(\mathrm{~L}) \times 50(\mathrm{~W}) \times 13(\mathrm{~T}) \mathrm{mm} 3$. Corresponding material classification could be made according to Table 1 .

Table 1. UL94-HB flammability test specifications

Classification
HBF
Burning rate $\mathrm{RB} \leq 40 \mathrm{~mm} / \mathrm{min}$ over a $100 \mathrm{~mm}$ span or the Burned length $\mathrm{LBH} \leq$
$\mathrm{HF}-125 \mathrm{~mm}$
After-flame time tA $\leq 2 \mathrm{~s}$ and dripping does not ignite cotton
After-flame time tA $\leq 2 \mathrm{~s}$ but dripping ignites cotton
BKZ-VB test: The flammability of prepared FPUF and the coated textiles was evaluated according to Swiss
flammability standard (BKZ) with a specific sample dimension (length: 160 mm, width: 60 mm and
thickness: 6 mm) for foams and (length: $160 \mathrm{~mm}$, width: $60 \mathrm{~mm}$ ) for coated textiles. In this test the air
dried specimen was placed in a vertical position and subjected to a standardized flame from the lower front
edge. The flame height of $20 \mathrm{~mm}$ was maintained and should burn constantly with sharp outlines. The
burner position was adjusted to $45^{\circ}$ so that the flame hits the specimen vertically in the middle of the lower
front edge. The flame is brought in contact with the foam for 15 sec and should be placed such that the
foam bottom is approximately $4 \pm 1 \mathrm{~mm}$ inside the flame tip. The test is considered to be passed when two
conditions are satisfied: Burned length LBV $<150 \mathrm{~mm}$; Burning duration tBV $<20 \mathrm{~s}$.




\section{Thermogravimetric (TGA) Measurements}

The thermal stability of FPUF samples was studied by NETZSCH TG 209 F1 instrument, with 2-5 mg sample under the nitrogen environment at a heating rate of $10{ }^{\circ} \mathrm{C} / \mathrm{min}$ from 50 to $800^{\circ} \mathrm{C}$. Three measurements were conducted for each sample system to ensure the reproducibility of the results.

\section{DIP Measurements}

Direct insert probe mass spectrometry (DIP-MS): DIP-MS is used to evaluate the degradation processes of the FPUF containing various phosphonamidates and further understand their flame retardant action. In principle, the sample to be analyzed is introduced into a quartz micro-cup in contact with a heating probe, the tip of which is inserted into the high vacuum chamber for the MS analysis 15. In this study, DIP-MS analyses were conducted for a 1-2 $\mu \mathrm{gm}$ of FPUF using a ThermoQuest FINNIGAN apparatus, where the probe was heated from $50{ }^{\circ} \mathrm{C}$ to $480{ }^{\circ} \mathrm{C}$ at a rate of $50 \mathrm{~K} / \mathrm{min}$ and the vacuum was applied at $10-6 \mathrm{mbar}$.

\section{RESULTS}

\section{Chemical Characterizationof Phosphonamidates}

BA-DOPO: 6-(benzylamino)-6H-dibenzo[c,e][1,2]-oxaphosphine-6-oxide, yield: 142.8 g (445mmol, $89 \%)$, m.p. $155-157^{\circ} \mathrm{C}$

1H-NMR $(\mathrm{CDCl} 3) \delta(\mathrm{ppm}): 7.96(\mathrm{dd}, \mathrm{J}=5.7,8.2 \mathrm{~Hz}, 1 \mathrm{H}), 7.92(\mathrm{dd}, \mathrm{J}=1.7,7.9 \mathrm{~Hz}, 1 \mathrm{H}), 7.89(\mathrm{ddd}, \mathrm{J}=$ 1.3, 7.6, 14.1 Hz, 1H), $7.65(\mathrm{tt}, 1.2,7.5 \mathrm{~Hz}, 1 \mathrm{H}), 7.44(\mathrm{ddt}, \mathrm{J}=0.8,3.0,7.4 \mathrm{~Hz}, 1 \mathrm{H}), 7.34(\mathrm{tt}, \mathrm{J}=1.3,7.8$ $\mathrm{Hz}, 1 \mathrm{H}), 7.18-7.30(\mathrm{~m}, 7 \mathrm{H}), 3.88-4.14(\mathrm{~m}, 3 \mathrm{H})$.

13C-NMR $(\mathrm{CDCl} 3) \delta(\mathrm{ppm}): 149.8,138.9,136.9,132.7,130.2,130.0,128.4,128.2,128.0,127.2,124.8$, $124.4(\mathrm{~d}, \mathrm{~J}=164 \mathrm{~Hz}) 124.2,123.5,121.9,120.5,44.9$.

31P-NMR (CDCl3) $\delta(\mathrm{ppm}): 15.5$.

IR (ATR) $v(\mathrm{~cm}-1)=3156(\mathrm{~m}), 2888(\mathrm{w}), 2605(\mathrm{w}), 2497(\mathrm{w}), 1640(\mathrm{w}), 1475(\mathrm{~m}), 1460(\mathrm{~m}), 1442(\mathrm{~m})$, $1428(\mathrm{~m}), 1225$ (s), $1199(\mathrm{~s}), 1149(\mathrm{~m}), 1119(\mathrm{~s}), 925(\mathrm{~m}), 900(\mathrm{~m}), 780(\mathrm{w}), 755(\mathrm{~s}), 734(\mathrm{~s})$.

MS (ESI) m/z (\%) 321 (1), 216 (9), 199 (7), 168 (20), 139 (10), 106 (100), 91 (7).

AA-DOPO: 6-(allylamino)-6H-dibenzo[c,e][1,2], oxaphosphinine 6-oxide, yield: 119.2g (440mmol, 88\%), m.p. $95^{\circ} \mathrm{C}$

${ }^{1} \mathrm{H}-\mathrm{NMR}\left(\mathrm{CDCl}_{3}\right) \delta(\mathrm{ppm}): 7.88-7.99(\mathrm{~m}, 3 \mathrm{H}), 7.92(\mathrm{dd}, J=1.7,7.9 \mathrm{~Hz}, 1 \mathrm{H}), 7.66(\mathrm{tt}, J=1.3,8.7,1 \mathrm{H})$, $7.48(\mathrm{ddt}, J=1.0,3.0,7.5 \mathrm{~Hz}, 1 \mathrm{H}), 7.35\left(\mathrm{~m}_{\mathrm{c}}, 1 \mathrm{H}\right), 7.20-7.26(\mathrm{~m}, 2 \mathrm{H}), 5.75-5.86(\mathrm{~m}, 1 \mathrm{H}), 5.19$ (dq, $J=1.4$, $17.1 \mathrm{~Hz}, 1 \mathrm{H}), 5.06(\mathrm{dq}, J=1.4,10.3 \mathrm{~Hz}, 1 \mathrm{H}), 3.39-3.60(\mathrm{~m}, 3 \mathrm{H})$.

${ }^{13} \mathrm{C}-\mathrm{NMR}\left(\mathrm{CDCl}_{3}\right) \delta(\mathrm{ppm}): 149.8,138.9,137.0,132.7,130.1,130.0128 .4,128.1127 .2,124.8,124.2$, $123.5,123.3,121.9,44.9$.

${ }^{31} \mathrm{P}-\mathrm{NMR}\left(\mathrm{CDCl}_{3}\right) \delta(\mathrm{ppm}): 15.9$.

IR (Film) v ( $\left.\mathrm{cm}^{-1}\right)=3179(\mathrm{~m}), 2855(\mathrm{w}), 1648(\mathrm{w}), 1592(\mathrm{w}), 1475(\mathrm{~m}), 1428(\mathrm{~m}), 1222(\mathrm{~s}), 1198(\mathrm{~m})$, $1152(\mathrm{~m}), 1142(\mathrm{~s}), 1054(\mathrm{w}), 923(\mathrm{~m}), 899(\mathrm{w}), 752(\mathrm{~s}), 715(\mathrm{~s})$.

MS (ESI) $m / z$ (\%) 271 (14), 216 (55), 199 (18), 168 (54), 139 (27), 56 (100).

EDA-b-DOPO : 6,6'-(ethane-1,2-diylbis(azanediyl))bis(6H-dibenzo[c,e][1,2]oxaphosphinine 6-oxide), yield : $102.5 \mathrm{~g}(210 \mathrm{mmol}, 84 \%)$

m.p. $267-270^{\circ} \mathrm{C}$

1H-NMR (Trifluoroethanol-d3) $\delta$ (ppm): 7.65-7.75 (m, 3H), 7.54-763 (m, 2H), 7.40-7.52 (m, 3H), 7.26$7.33(\mathrm{mc}, 1 \mathrm{H}), 6.97-7.19(\mathrm{~m}, 5 \mathrm{H}), 6.81(\mathrm{dd}, \mathrm{J}=1.1,7.9 \mathrm{~Hz}, 1 \mathrm{H}), 7.59(\mathrm{dd}, \mathrm{J}=1.1,8.0 \mathrm{~Hz}, 1 \mathrm{H}), 2.73-2.91$ $(\mathrm{m}, 2 \mathrm{H}), 2.58-2.72(\mathrm{~m}, 2 \mathrm{H})$.

13C-NMR (Trifluoroethanol-d3) $\delta$ (ppm): 150.8, 150.5, 139.3, 139.1, 135.8, 135.7, 132.5, 132.4, 131.4, $131.3,130.3,130.2,126.8,126.7,126.1,125.8,123.3,123.2,121.8,121.5,43.6,43.4$.

31P-NMR (Trifluoroethanol-d3) $\delta$ (ppm): 21.4, 20.7. 
IR (Film) v (cm-1) = $3159(\mathrm{~m}), 2877(\mathrm{w}), 1598(\mathrm{w}), 1476(\mathrm{~m}), 1446(\mathrm{~m}), 1196(\mathrm{~s}), 1146(\mathrm{~m}), 1116(\mathrm{~s}), 922$ (s), $747(\mathrm{~s}), 711(\mathrm{~m})$.

MS (ESI) $\mathrm{m} / \mathrm{z}(\%) 488(100)$.

Pip-b-DOPO : 6,6'-(piperazine-1,4-diyl)bis(6H-dibenzo[c,e][1,2]oxaphosphinine 6-oxide), yield : 110.5g (212 mmol, 85\%), m.p. $320^{\circ} \mathrm{C}$

1H-NMR (Trifluoroethanol-d3) $\delta$ (ppm): 7.91 (mc, 2H), $7.84(\mathrm{mc}, 2 \mathrm{H})$, 7.56-7.66 (m, 4H), $7.38(\mathrm{mc}, 2 \mathrm{H})$, 7.24 (mc, 2H), $7.12(\mathrm{mc}, 2 \mathrm{H}), 7.06$ (mc, 7.06), 2.99 (mc, 8H).

13C-NMR (Trifluoroethanol-d3) $\delta$ (ppm): 151.2, 139.8, 136.0, 132.6, 131.2, 130.6, 127.0, 126.1, 123.5, 123.4, 121.9, 121.8, 45.7.

31P-NMR (Trifluoroethanol-d3) $\delta$ (ppm): 19.5 .

IR (Film) v (cm-1) = $2856(\mathrm{w}), 1596(\mathrm{w}), 1476(\mathrm{w}), 1428(\mathrm{w}), 1369(\mathrm{w}), 1230(\mathrm{~s}), 1205(\mathrm{~m}), 1147(\mathrm{~m})$, $1114(\mathrm{~m}), 969(\mathrm{~m}), 901(\mathrm{~s}), 747(\mathrm{~s}), 707(\mathrm{~s})$.

MS (ESI) $\mathrm{m} / \mathrm{z}(\%) 514$ (100).

\section{Fire Tests}

The virgin FPUF has a density of around $47 \mathrm{~kg} / \mathrm{m}^{3}$ whereas addition of phosphonamidates/ amino DOPO derivatives increases the density of the foams by approximately $2-5 \mathrm{~kg} / \mathrm{m}^{3}$. The flammability data of the FPUFs are shown in table 2.

Table 2. Flammability of FPUFs

\begin{tabular}{|c|c|c|c|}
\hline Flame Retardant & Conc. & BKZ test & UL 94 HBF rating \\
\hline \multirow{2}{*}{ Blank } & & Classification & Rating $^{\mathbf{a}}$ \\
\hline \multirow{2}{*}{ DOPO } & - & NO & HBF \\
\hline \multirow{3}{*}{ AA-DOPO } & $5 \%$ & 5 & - \\
\cline { 2 - 4 } & $10 \%$ & Not Applicable & HF-2 \\
\cline { 2 - 4 } & $10 \%$ & 5 & HF-1 \\
\hline \multirow{2}{*}{ BA-DOPO } & $5 \%$ & 5 & X \\
\cline { 2 - 4 } & $10 \%$ & 5 & HF-2 \\
\hline \multirow{2}{*}{ EDA-b-DOPO } & $5 \%$ & 5 & HF-1 \\
\cline { 2 - 4 } & $10 \%$ & 5 & HF-2 \\
\hline \multirow{2}{*}{ Pip-b-DOPO } & $5 \%$ & 5 & HF-1 \\
\cline { 2 - 4 } & $10 \%$ & 5 & HBF \\
\hline \multirow{2}{*}{ TCPP } & $5 \%$ & 5 & HF2 \\
\cline { 2 - 4 } & $10 \%$ & 5 & HF2 \\
\hline \multirow{2}{*}{ EXOLIT OP 560 } & $5 \%$ & 5 & Not Applicable \\
\cline { 2 - 4 } & $10 \%$ & & 5 \\
\hline
\end{tabular}

Unlike the commercially available flame retardants (TCPP and EXOLIT OP 5060) the phosphonamidates synthesized in this work are solids. Incorporation of solid flame retardants in PU foams poses some challenges in their manufacturing. The solid flame retardant additives need to be well dispersed in the polyol to get reproducible fire results and good mechanical properties. As seen from table 2, we could prepare PU foams with all flame retardant additives even at 10\% concentration except for Exolit OP 5060 and DOPO. The foams collapsed at $10 \%$ concentrations for these additives which may be due to possible side reactions with the TDI and instability of the cells of PU foams. The phosphonamidates synthesized in this work exhibited superior fire performance as compared to the commercially available flame retardants (TCPP, EXOLIT OP 5060). EDA-b-DOPO exhibited the best flame retardant performance as compared to other amino- DOPO derivatives. PU Foam containing only 5\% EDA-b-DOPO is rated as HF1. All other 
phosphonamidates except BA-DOPO exhibited HF1 rating at $10 \%$ concentration. This clearly indicates superior flame retardant characteristics of the phosphonamidates as compared the commercially available flame retardant additives.

Table 3 shows the flame retardant characteristics of polyurethane coated polyester fabrics. It can be seen from the table that PU coated polyester fabric burns completely whereas addition of different flame retardants to the PU coating improves its flame retardancy. The table reports the minimum concentration of additive required to achieve the BKZ class 5 classification. Only 25\% EDA-b-DOPO ( based on solid content of PU) is needed to achieve the BKZ classification whereas the commercially available additives like APYROL FFD and Decabrom/ Antimony trioxide system requires much higher concentration. Furthermore the time of burning and the smoke generation of the EDA-b-DOPO containing coatings are lower than the commercial flame retardants.

Table 3. Flame retardant behavior of PU coated polyester textiles

\begin{tabular}{|c|c|c|c|c|c|c|}
\hline \multirow[b]{2}{*}{ Formulation* } & \multirow[b]{2}{*}{$\begin{array}{c}\text { Density } \\
\mathrm{g} / \mathrm{m}^{2}\end{array}$} & \multirow[b]{2}{*}{$\begin{array}{l}\text { Thickness } \\
(\mathrm{mm})\end{array}$} & \multirow[b]{2}{*}{$\begin{array}{l}\text { Time of } \\
\text { burning }\end{array}$} & \multirow[b]{2}{*}{$\begin{array}{c}\text { Average } \\
\text { BKZ grade }\end{array}$} & \multicolumn{2}{|c|}{ Observations } \\
\hline & & & & & Smoke & Dripping \\
\hline $10 \% \mathrm{CMC}+1 \%$ antifoamer $+10 \%$ fixer & 0.0151 & 0.144 & $>20 \mathrm{~s}$ & 4 & High & yes \\
\hline $\begin{array}{l}25 \% \text { EDA-b-DOPO }+10 \% \mathrm{CMC}+1 \% \\
\text { antifoamer }+10 \% \text { fixer }\end{array}$ & 0.0298 & 0.237 & $<10 \mathrm{~s}$ & 5 & Small & little \\
\hline $\begin{array}{l}30 \% \text { Decabrom/Antimony trioxide }+10 \% \\
\mathrm{CMC}+1 \% \text { antifoamer }+10 \% \text { fixer }\end{array}$ & 0.0346 & 0.254 & $>20 \mathrm{~s}$ & 4 & Medium & yes \\
\hline $\begin{array}{l}50 \% \text { Apyrol FFD }+10 \% \mathrm{CMC}+1 \% \\
\text { antifoamer }+10 \% \text { fixer }\end{array}$ & 0.0433 & 0.334 & $<20$ s & 5 & High & yes \\
\hline
\end{tabular}

*All coating paste recipe had 100 grams of TUBICOAT PUS dispersion. The solid content of the PU dispersion was $50 \%$. The $\%$ of other additives in the coating paste is based on the solid content of the PU.

\section{Thermal Decomposition Studies of FPUF}

Thermal decomposition studies of modified FPUFs were carried using TGA and DIP-MS analysis to determine the thermal characteristics of foam and to understand the mode of action of the phosphonamidates. Figure 1 shows the TGA data of elected phosphonamidates( $10 \%)$ containing PU foams. It can be seen from the figure that the degradation of blank foam takes place in two distinct stages, i.e. in the range of $200^{\circ} \mathrm{C}-300{ }^{\circ} \mathrm{C}$ and $300-400{ }^{\circ} \mathrm{C}$. Similar observations were shown in previous studies[4, 18]. The first stage is characterized by cleavage of urethane bonds by depolymerization or rearrangement reactions to form TDI, Diaminotoluene and polyols. The second stage is characterized by decomposition reactions mostly involving polyether polyol. There is practically no char left after the $400{ }^{\circ} \mathrm{C}$. Addition of phosphonamidates doesn't interfere with the thermal decomposition of the PU foams. Like blank PU foams there is no char left after $400{ }^{\circ} \mathrm{C}$. This clearly indicates the gas phase action the phosphonamidates compounds. EDA-b-DOPO foams show thermally stable intermediate formation between $250-350{ }^{\circ} \mathrm{C}$ which may indicate some kind of condensed phase action. AA-DOPO and BA-DOPO foams seem to have similar thermal decomposition as the blank foam. 


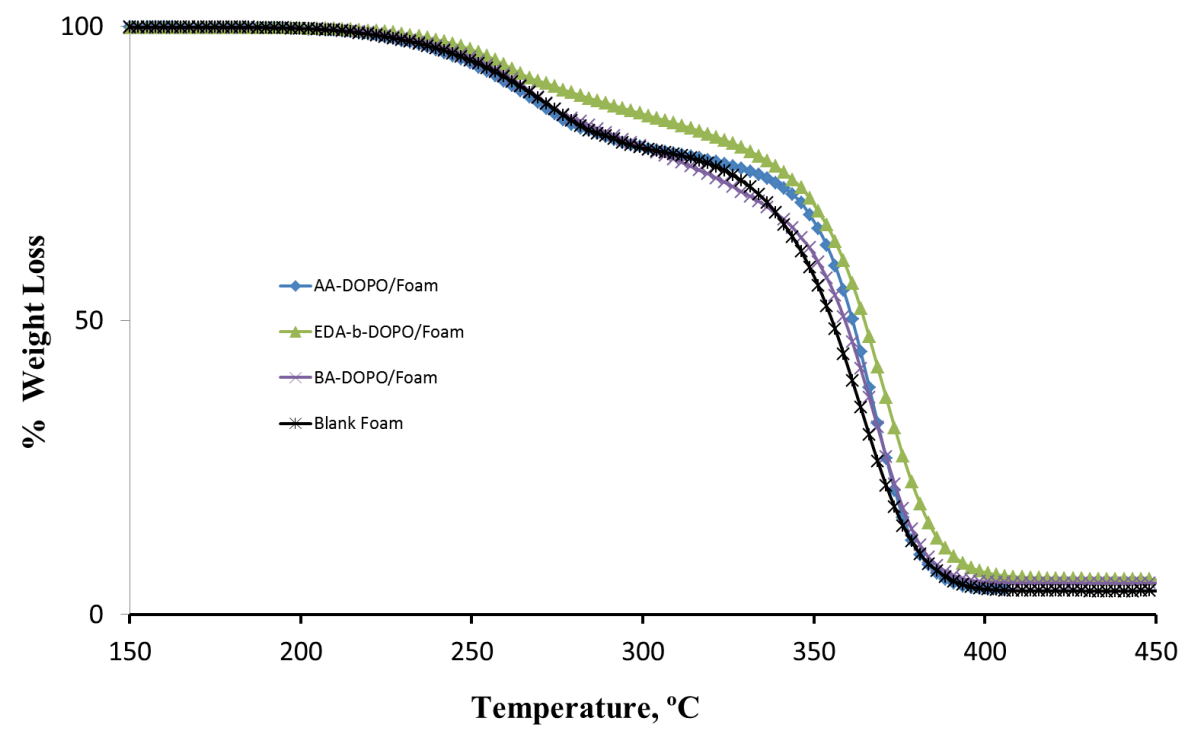

Figure 1. TGA curves of phosphonamidates $(10 \%)$ containing PU foams

To further elucidate the decomposition products formed during the thermal decomposition process of the PU foams, evolved gas analysis was performed using the DIP-MS technique (figure 2).

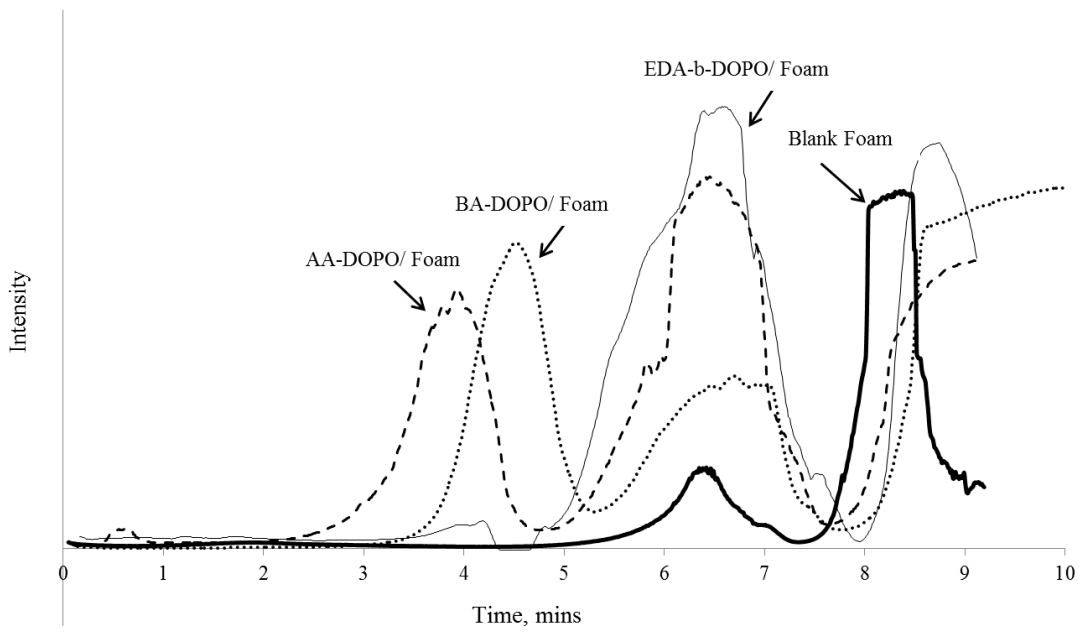

Figure 2. Total ion chromatogram of PU foams: AA-DOPO/Foam, BA-DOPO/ Foam, EDA-b-DOPO/ Foam , Blank foam 
Figure 2 shows the total ion chromatogram for PU foams formed at different time (corresponding to different temperature). It is clear that blank foam decomposes in two main steps with peaks centered at 6.5 mins and 8.5 mins corresponding to $370{ }^{\circ} \mathrm{C}$ and $470{ }^{\circ} \mathrm{C}$ respectively. The extracted ion chromatogram of the first stage indicates the release of TDI and diaminotoluene (figure $3 \mathrm{~A}$ ) and the second stage shows the decomposition products of the polyols ( figure $3 \mathrm{~B}$ ) .
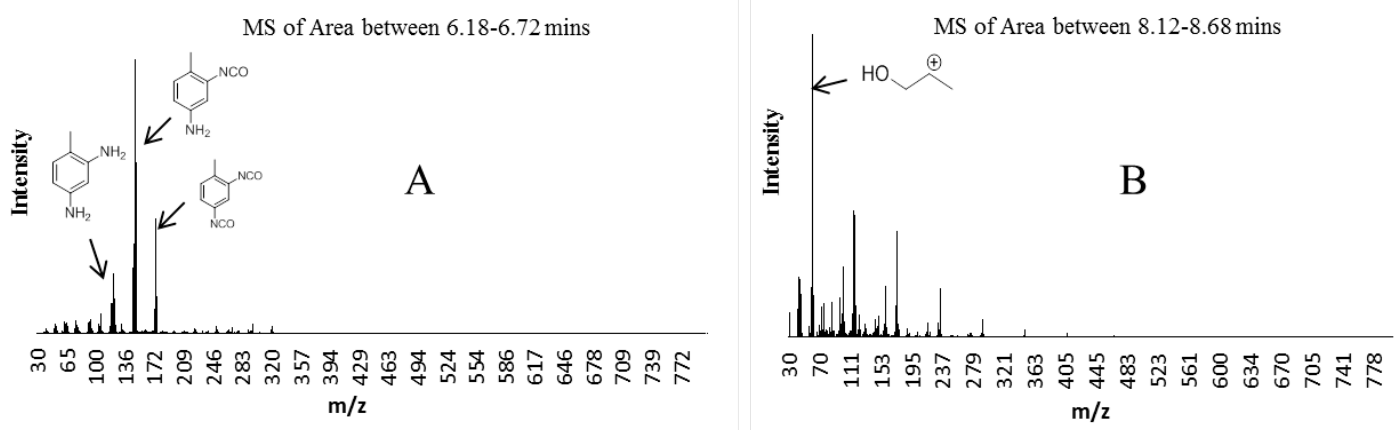

Figure3. Extracted ion chromatograms of first and $2^{\text {nd }}$ stage decomposition of blank PU foam

The DIP-MS data of blank foam are similar to that obtained in the TGA studies discussed in an earlier work[18]. The apparent shift of the two main stages of decomposition to higher temperatures in DIP-MS data as compared to the TGA data is due to the higher heating rates $(50 \mathrm{~K} / \mathrm{min})$ used in the DIP-MS measurements. Phosphonamidate containing foams (except EDA-b-DOPO) clearly shows three stage decomposition process. In addition to the two main stage of thermal decomposition as discussed earlier the etotal ion chromatogram for AA-DOPO and BA-DOPO foams (figure1) shows an additional earlier peak corresponding to the release of respective phosphonamidates and their decomposing products centered at 3.5 mins and 4.5 mins respectively. The extracted ion chromatogram showing release of AA-DOPO and PA-DOPO for this earlier stage is shown in figure 4.
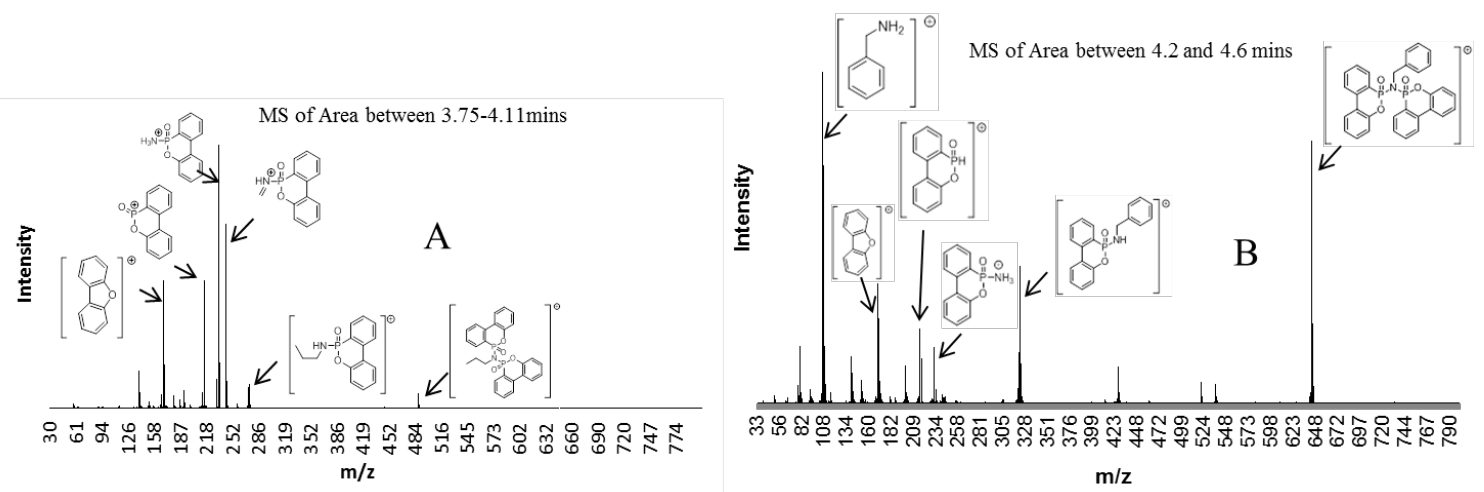

Figure 4. Extracted ion chromatogram of early stage decomposition of (A) AA-DOPO foam (B) BA-DOPO foam

The actual decomposition of the PU polymer is not affected by presence of the phosphonamidates . The TDI/ diamino toluene release (first stage) and decomposition products formed from polyol (second stage) is exactly at the same temperatures range as the blank foam. Unlike AA-DOPO and BA-DOPO containing foams, extracted ion chromatogram of EDA-b-DOPO indicates that most of the phosphorus species formed from the decomposition of EDA-b-DOPO, is released during the thermal decomposition of the polyols( figure 5). Figure 5 shows the extracted ion chromatogram of EDA-b-DOPO foam in the region where polyol decomposition products are observed. This might explain the higher flame retardant effectiveness of the EDA-b-DOPO as compared to the other phosphonamidates. Similar observations were also made for 
Pip-b-DOPO. As the TDI based PU foam contains more (wt. \%) polyol than the TDI, it is useful to have most phosphorus species released during the

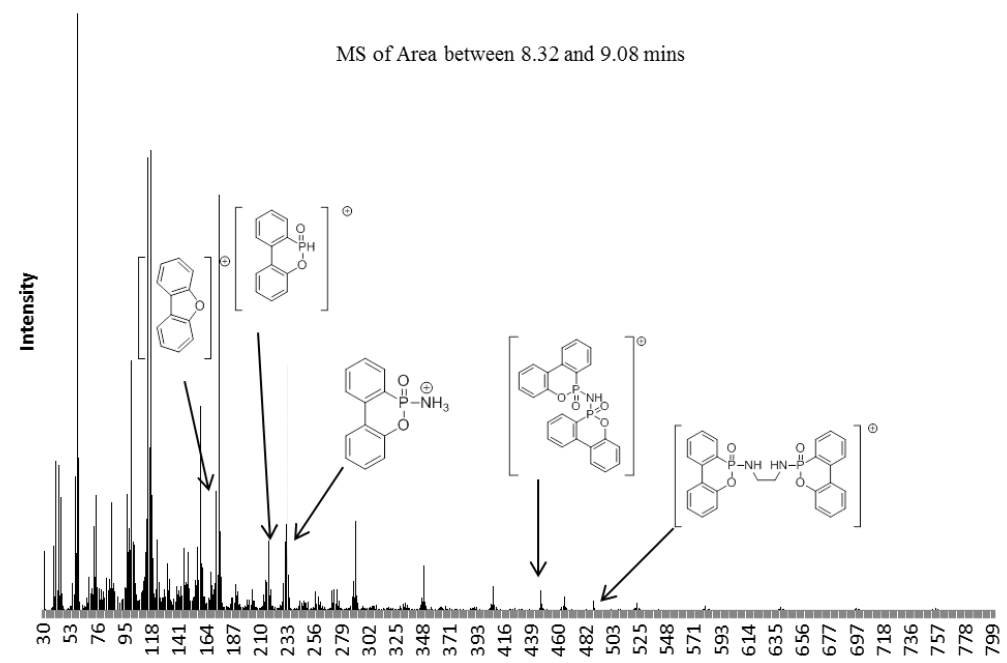

Figure 5. Extracted ion chromatogram of EDA-b-DOPO foam at polyols decomposition stage

decomposition of polyols. EDA-b-DOPO has higher molecular weight and thus is only release in the later stage of thermal decomposition of PU foams and thus improves is effectiveness as a flame retardant.

\section{CONCLUSION}

In this work we have synthesized various amino-DOPO derivatives (phosphonamidates) and applied them flame retardant additive in various polyurethane based systems. The PU based materials (foams and coated PET fabrics) exhibit superior flame retardant behavior as compared to the commercially available solutions. EDA-b-DOPO shows better flame retardant behavior on PU foams as compared to the other phosphonamidates. The thermal decomposition studies using TGA and DIP-MS indicate gas phase action for the phosphonamidates.

\section{ACKNOWLEDGEMENTS}

The authors thank Foampartner, Switzerland for helpful technical assistance and financial support. This research was also funded by CTI, commission for technology and innovation, Switzerland. Finally the authors are thankful to Mrs. Elisabeth Michel for her help in series of analytical measurement and Dr. Daniel Rentsch for all NMR measurements.

\section{REFERENCES}

[1] Lu S-Y, Hamerton I, Recent developments in the chemistry of halogen-free flame retardant polymers, Progress in Polymer Science, 2002;27: 1661-712.

[2] Darnerud PO, Toxic effects of brominated flame retardants in man and in wildlife, Environment international, 2003;29: 841-53.

[3] Gaan S, Rupper P, Salimova V, Heuberger M, Rabe S, Vogel F, Thermal decomposition and burning behavior of cellulose treated with ethyl ester phosphoramidates: Effect of alkyl substituent on nitrogen atom, Polymer Degradation and Stability, 2009;94: 1125-34. 
[4] Liang S, Neisius M, Mispreuve H, Naescher R, Gaan S, Flame retardancy and thermal decomposition of flexible polyurethane foams: Structural influence of organophosphorus compounds, Polymer Degradation and Stability, 2012;97: 2428-40.

[5] Brehme S, Schartel B, Goebbels J, Fischer O, Pospiech D, Bykov Y, Döring M, Phosphorus polyester versus aluminium phosphinate in poly(butylene terephthalate) (PBT): Flame retardancy performance and mechanisms, Polymer Degradation and Stability, 2011;96: 875-84.

[6] Ho T-H, Hwang H-J, Shieh J-Y, Chung M-C, Thermal and physical properties of flame-retardant epoxy resins containing 2-(6-oxido-6H-dibenz $\langle\mathrm{c}, \mathrm{e}\rangle \quad\langle 1,2\rangle$ oxaphosphorin-6-yl)-1,4-naphthalenediol and cured with dicyanate ester, Polymer Degradation and Stability, 2008;93: 2077-83.

[7] Hu Z, Chen L, Zhao B, Luo Y, Wang D-Y, Wang Y-Z, A novel efficient halogen-free flame retardant system for polycarbonate, Polymer Degradation and Stability, 2011;96: 320-27.

[8] Granzow A, Flame retardation by phosphorus compounds, Accounts of Chemical Research, 1978;11: $177-83$.

[9] König A, Kroke E, Methyl-DOPO_-a new flame retardant for flexible polyurethane foam, Polymers for Advanced Technologies, 2011;22: 5-13.

[10] Schäfer A, Seibold S, Lohstroh W, Walter O, Döring M, Synthesis and properties of flame-retardant epoxy resins based on DOPO and one of its analog DPPO, Journal of Applied Polymer Science, 2007;105: 685-96.

[11] Shieh J-Y, Wang C-S, Synthesis of novel flame retardant epoxy hardeners and properties of cured products, Polymer, 2001;42: 7617-25.

[12] Artner J, Ciesielski M, Ahlmann M, Walter O, Doering M, Perez RM, Altstaedt V, Sandler JKW, Schartel B, A novel and effective synthetic approach to 9,10-dihydro-9-oxa-10-phosphaphenanthrene-10oxide (DOPO) derivatives, Phosphorus Sulfur and Silicon and the Related Elements, 2007;182: 2131-48.

[13] Neisius M, Gaan S, Liang S, Novel derivatives of DOPO as flame retardant additives for polymers, 245th ACS National Meeting \& Exposition, New Orleans, LA, United States, 2013.

[14] Gaan S, Neisius M, Mercoli P, Liang S, Mispreuve H, Naescher R, Phosphonamidates, production methods and flame retardant applications, WO 2013020696 A2 2013.

[15] Neisius NM, Shuyu L, Henri M, Sabyasachi G. Recent Developments in Flame Retardancy of Flexible Polyurethane Foams. In. Recent Developments in Flame Retardancy of Flexible Polyurethane Foams. American Chemical Society, 2012, pp. 251-70.

[16] van der Veen I, de Boer J, Phosphorus flame retardants: Properties, production, environmental occurrence, toxicity and analysis, Chemosphere, 2012;88: 1119-53.

[17] Rahman F, Langford KH, Scrimshaw MD, Lester JN, Polybrominated diphenyl ether (PBDE) flame retardants, Science of The Total Environment, 2001;275: 1-17.

[18] Lefebvre J, Bastin B, Le Bras M, Duquesne S, Paleja R, Delobel R, Thermal stability and fire properties of conventional flexible polyurethane foam formulations, Polymer Degradation and Stability, 2005;88: 28-34. 